\title{
Is There Broad-Based Support in High-Income Countries for COVID-19 Vaccine Donation? Evidence from Seven Countries
}

\author{
Laurence S. J. Roope ${ }^{1,2}$ (1) Adrian Barnett ${ }^{3} \cdot$ Paolo Candio ${ }^{1,2,4} \cdot$ Mara Violato $^{1,2} \cdot$ Raymond Duch $^{5} \cdot$ Philip M. Clarke $^{1,2,6}$
}

Accepted: 26 October 2021 / Published online: 29 November 2021

(c) The Author(s) 2021

\begin{abstract}
Background Many high-income countries (HICs) have now vaccinated a substantial proportion of their population against COVID-19. Many low-income countries (LICs) may need to wait until at least 2022 before even the most vulnerable $20 \%$ of their populations are vaccinated. Beyond ethical considerations, some redistribution of doses would reduce the risk of the emergence and spread of new variants and benefit the economy, both globally and in donor countries. However, the willingness of HIC governments to donate vaccine doses is likely to depend on public support. While previous work has indicated strong average levels of public support in HIC for donation, little is known about how broad-based this support is.

Objective To investigate the extent to which support for donation holds across both pre-specified and exploratory subgroups. Methods From 24 November-28 December 2020 we conducted an online survey of 8209 members of the general public in seven HIC (Australia, Canada, France, Italy, Spain, UK and USA). We conducted tests of proportions and used Bayesian ordinal logistic regression models to assess the extent of support for donation across population subgroups.

Results We found broad-based support for donations in terms of age, gender, socio-economic status and political ideology. We found no strong evidence that support for donations was higher among those with greater income or a university education. Support for donation among those on the political right and centre was lower than on the left, but $51 \%$ (95\% confidence interval 48-53\%) of respondents who identified with the right supported some level of donation. Those in the more altruistic half of the sample (as captured by willingness to donate money to a good cause) were more likely to support donation than those who were not, but around half of the less altruistic group supported some level of donation.

Conclusion There is broad-based support for policymakers in HICs to donate some of their countries' COVID-19 vaccine doses for distribution to LICs.
\end{abstract}

Laurence S. J. Roope

Laurence.roope@dph.ox.ac.uk

1 Health Economics Research Centre, Nuffield Department of Population Health, University of Oxford, Oxford, UK

2 National Institute for Health Research Oxford Biomedical Research Centre, John Radcliffe Hospital, Oxford, UK

3 Australian Centre for Health Services Innovation and Centre for Healthcare Transformation, School of Public Health and Social Work, Queensland University of Technology, Brisbane, QLD, Australia

4 Centre for Economics of Obesity, University of Birmingham, Birmingham, UK

5 Nuffield College, University of Oxford, Oxford, UK

6 Melbourne School of Population and Global Health, Centre for Health Policy, University of Melbourne, Melbourne, VIC, Australia

\section{Key Points for Decision Makers}

Previous research has found high average levels of support among the general public in high-income countries for donating COVID-19 vaccine doses to low-income countries, but little is known about how broad-based this support is.

This study investigated the extent of support for donation in seven high-income countries across several subgroups.

Our results suggest broad-based support for donations in terms of age, gender, socio-economic status and political ideology. 


\section{Introduction}

In the fight against the COVID-19 pandemic, high-income countries (HICs) have been able to secure preferential supply for large numbers of doses of several COVID-19 vaccines [1]. A number of HICs have pre-purchased supplies exceeding their population size. For example, the USA has reserved more than 1.2 billion doses [2] and Canada has premarket commitments covering more than nine doses per person [1]. Unfortunately, access to vaccines in the rest of the world is proceeding at a much slower pace. Despite pledges by G20 leaders and the efforts of the COVAX Facility to ensure equal global access to COVID-19 vaccines, some low-income countries (LICs) may need to wait until at least 2022 before even the most vulnerable $20 \%$ of their populations are vaccinated [3].

Against this backdrop, there have been increasingly vocal calls for HICs to donate a proportion of their vaccine doses [4-6]. The G7 countries have now pledged to donate 1 billion doses over the next year [7]. However, with many countries facing a prolonged period with barely any vaccine doses, and an estimated 11 billion doses needed to significantly reduce transmission of the virus globally, current commitments have been described as being too little and too slow [8]. ${ }^{1}$

Leaving aside questions of moral responsibility, there are strong arguments that it is in HICs' self-interest to donate a portion of their doses to LICs. Redistributing doses would reduce the risk of the emergence and spread of new variants, some of which could potentially be resistant to current vaccines. It has also been predicted that some redistribution would benefit the economy, both globally and in donor countries [10]. ${ }^{2,3}$ However, notwithstanding compelling arguments, the willingness of HIC governments to make sufficient COVID-19 vaccine doses available to LICs is likely to hinge largely on the extent to which the general public are supportive. In recent online survey work, we provided evidence of strong public support for donations to LICs that was consistent across seven HICs [12]. We documented evidence that, in each country, between $48 \%$ and $56 \%$ supported some level of donation of vaccine doses [12]. Moreover, of

\footnotetext{
${ }^{1}$ Donating vaccine doses in a pandemic is not without precedent. In the H1N1 pandemic the USA pledged to donate $10 \%$ of the US' vaccine supply, which was supported by the general public [9].

${ }^{2}$ In contrast, the economic cost of vaccine nationalism (where a few countries push to gain preferential access) is potentially high, with a recent report suggesting it could cost up to $\$ 1.2$ trillion per year to the world's economy [11].

${ }^{3}$ If redistribution reduced the risk of emergence of new variants, this in itself could be immensely valuable economically to donor countries.
}

those who supported vaccine donations, over $70 \%$ favoured donating at least $10 \%$ of their country's doses [12].

Beyond average levels of support, the willingness of governments to donate vaccine doses could also be influenced by how broad-based the support is. For example, even with some majority support, governments may be reluctant to donate vaccines if this support is heavily polarised along sociodemographic and, especially, political lines. In such circumstances, government efforts to donate doses could be beset with political hurdles, reducing the time and political capital available to deal with other pressing issues. ${ }^{4}$ In this study, we therefore extended the analyses reported in Clarke et al. [12] by investigating the extent to which support for donation holds across a number of pre-specified subgroups [14] - as well as some additional exploratory subgroups. Our pre-specified hypotheses were that there would be greater support for donations among respondents who were more altruistic (as captured by self-reported willingness to donate money to a good cause), had a university degree, identified politically as 'left' or 'centre' (vs. 'right'), and of above average income [14]. We also investigated whether there were differences by age and gender.

\section{Data and Methods}

\subsection{Data}

The data were collected as part of the first wave of the CANDOUR study. ${ }^{5}$ Overall, this first wave involved 15,536 individuals from 13 countries. Respondents completed an anonymous survey between 24 November and 28 December 2020 using Qualtrics web-based software. Quota sampling (and in five countries additional weighting) was used to obtain a sample that reflected the distribution of age, education, gender and region in each country. ${ }^{6}$

As in Clarke et al. [12], the present study used information from 8,209 individuals aged 18 years or more from the subset of HIC in the sample (Australia, Canada, France,

\footnotetext{
$\overline{4}$ This would not be the first example of a COVID-19 response policy that proved polarising along political lines. The timing and extent of lockdowns and social distancing measures have been contentious in many countries, with those on the political right often less supportive than those on the left. In the US, policies requiring use of masks have also been polarising, with much greater support on the left than on the right [13].

5 The CANDOUR study is a multi-country survey study designed to address a variety of research questions regarding public preferences for the allocation of scarce COVID-19 vaccines. For details, visit https://oxford-candour.com/.

${ }^{6}$ Full details of the sampling and post-sampling weighting, which was performed using a 'raking' procedure, are provided in a supplementary technical appendix to Duch et al. [15].
} 
Italy, Spain, the UK and the USA). ${ }^{7}$ As described in [12], we adapted a question previously used in the context of H1N1 [9] and asked whether respondents supported donating some COVID-19 vaccine doses for distribution to poor countries with insufficient resources to buy their own vaccines. The exact wording was:

Some people feel that the [HIC name] government should donate some of the COVID-19 vaccine doses it has purchased for distribution to poor countries that do not have the resources to buy their own vaccine.

Which of the following statements most closely matches your view:

- The [HIC name] government should not donate any vaccine it has purchased

- The [HIC name] government should donate less than $10 \%$ of its purchased vaccine

- The [HIC name] government should donate $10 \%$ of its purchased vaccine

- The [HIC name] government should donate more than $10 \%$ of its purchased amount of vaccine

- Do not know

- Prefer not to say

Overall proportions of each response category for each country, including 95\% confidence intervals (CIs), were reported by Clarke et al. [12]. In this study, we hypothesised that, in each country, the responses favouring a greater emphasis on vaccine provision for poorer countries would vary by levels of altruism, income, political ideology and education, and be greater among:

(a) The more altruistic half of the sample;

(b) The half of the sample with higher equivalised household income;

(c) Those who identify as left/centre politically versus those who identify as right politically;

(d) Those with at least a university degree.

In exploratory analyses, we also aimed to test whether the responses were heterogenous in subgroups defined by:

(e) Age;

(f) Gender; and

(g) Willingness to take risks with health.

The more 'altruistic' half of the sample were identified according to responses to a question that asked:

\footnotetext{
7 Three respondents were removed from our analysis: one respondent who claimed to be aged only 15 , and two respondents who claimed to be older than 105 .
}

Imagine the following situation: Today you unexpectedly received \$700 [US version: amendments by country to currency and amount]. How much of this amount would you donate to a good cause?

- [Enter amount]

- Do not know

- Prefer not to say

There were some missing data (including "do not know" and "prefer not to say") for education (1.5\%), income (24.3\%), political ideology (15.9\%), altruism (39.9\%) and willingness to take risks (7.0\%). We wished to avoid excluding these responses from the analysis, particularly in light of the fact that unanswered responses to these questions might group people with similar attitudes to donating vaccines. To avoid excluding these responses, we included 'unanswered' as a separate category.

The household income data were equivalised for household composition using the Modified OECD Equivalence scale. A three-category variable was created for "high income" (on or above the median), "low income" (below the median) and "unanswered".

We created a three-category variable for altruism based on the donation amount. The first category combined "unanswered", "do not know" and "prefer not to answer". The next two categories were "meagre", which was below the median donation amount for that country, and "generous", which was on or above the median donation amount for that country. Stratifying by country for this variable was necessary because each country had different amounts and units of currency.

Political ideology was identified by asking respondents to indicate where their political views lay on a scale from 0 ("left") to 10 ("right"). The centre of the distribution on this scale varied greatly between countries. To make a more comparable variable for this multi-country analysis we split each country's results into tertiles to give a relative measure of political leaning within countries. So this variable had four categories: left, centre, right and unanswered.

For education we created a variable with four categories: primary education or less, secondary, university degree and unanswered.

Willingness to take risks with health was assessed based on a widely used risk-preference indicator originating from the German Socio-Economic Panel (SOEP) survey. Respondents were again asked to use a scale from 0 ("completely unwilling to take risks") to 10 ("very willing to take risks"). We divided this into two groups defining those with a score of $0-5$ as "unwilling" and those with a score of 6-10 as "willing". We added a third group of "unanswered". 
For gender, we looked at male gender versus all other responses. For age, the categories were up to age 39, 40-59 and $60+$ years.

\subsection{Statistical Methods}

In our main analysis, we used a Bayesian ordered logistic model with the following four ordered categories:

- Should donate more than $10 \%$;

- Should donate $10 \%$;

- Should donate less than $10 \%$;

- Should not donate.

Answers of "Prefer not to say" or "Do not know" were excluded for this analysis.

Our ordinal logistic regression model assumed a latent normal distribution for donation willingness with three cutpoints that defined the observed ordinal response [16]. The model was formulated as a cumulative logit model and we assumed that the odds ratio for a one unit change in the predictors was the same across the ordinal responses. The odds ratios are interpreted as the odds of moving to a higher category (greater willingness to donate). The ordered cutpoints can be unequally spaced to allow for differences in the proportions of responses in the four categories, and we allowed the cut-points to vary by country, permitting differences between countries in the proportions supporting donation.

We examined the association with this ordinal outcome and the independent variables of age (up to 39, 40-59, 60+ years), gender (male, not male), education (primary or less, secondary, university degree, unanswered), altruism (meagre, generous, unanswered), income (high, low, unanswered), political ideology (left, centre, right, unanswered) and willingness to take risks with health (unwilling, willing, unanswered). We fitted each variable independently and then used all seven in a multiple variable model.

Each model was fitted as a Bayesian ordinal logistic regression model using random effects by country. We allowed the effect of the independent variables to vary by country as we had a strong expectation of differences between countries. For example, the education level "university" is not fixed over countries but instead varies by country around an overall effect. Estimates were therefore made both at country level and overall. We estimated the mean odds ratio and a Bayesian $95 \%$ credible interval.

To test whether the independent variables did vary by country, we fitted an alternative fixed-effects model and compared the model fit using the deviance information criterion (DIC), which balances model complexity and fit [17,
18]. We compared the more complex model containing a random effect in each country with the simpler model containing a fixed effect. All models used a random intercept in each country to account for overall differences between countries in the willingness to donate vaccines.

The Bayesian models were fitted in WinBUGS (version 1.4.3) and the plots were made using $\mathrm{R}$ (version 4.1.1). We used two chains thinned by three with a burn-in and sample of 4,000. We visually checked the convergence and mixing of the chains. We used vague normal priors for the mean parameters in the ordinal regression model and vague gamma priors for the inverse variances. The Bayesian models and R code are freely available on github (https://github. com/agbarnett/donate).

We used Bayesian posterior probabilities (BPPs) to compare the groups. The BPPs examine the odds ratios for a group relative to the reference category, for example, oldest age group relative to youngest. The BPP is the estimated probability that the odds ratio is equal to one (the null hypothesis).

It could be argued that there is a case for interpreting responses of "do not know" or "prefer not to say" as being less supportive of donation than a response that clearly expresses some support. As a sensitivity analysis, we therefore repeated the above analysis including the unanswered donation responses, with the following five ordered categories:

- Should donate more than $10 \%$;

- Should donate $10 \%$;

- Should donate less than $10 \%$;

- Prefer not to say/Do not know;

- Should not donate.

As above, we used an ordinal logistic regression model assuming a latent normal distribution for donation willingness, this time with four cut-points that defined the observed ordinal response [16].

\section{Results}

As reported by Clarke et al. [12], the overall proportions supporting donation were more than double the proportion who did not support donating (Fig. 1). The greatest levels of support for donation were from the most highly educated; those on the political left; those who were most altruistic; the young and those willing to take risks with health (Table 1). However, in every variable-category, there was much more support for some level of donation than there 
Fig. 1 Overall proportions in each country supporting some level of donation. (1) Figure created by authors based on results in Clarke et al. (2021)'s Table 1 [12]. (2) Sample sizes: Australia (1364); Canada (1150); France (1145); Italy (1081); Spain (1153); UK (1165); USA (1150)

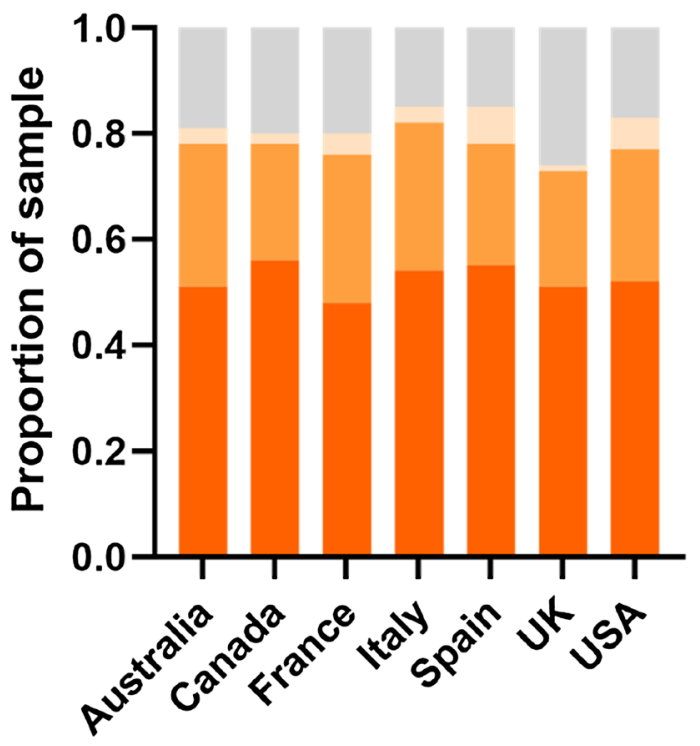

Donate

Don't Know

Prefer not say

Should not donate

Table 1 Preferences for willingness to donate COVID-19 vaccines

\begin{tabular}{|c|c|c|c|c|c|c|c|c|}
\hline \multirow[t]{2}{*}{ Variable } & \multirow[t]{2}{*}{ Category } & \multicolumn{4}{|c|}{ Willing to donate } & \multirow[b]{2}{*}{$\begin{array}{l}\text { Should not donate } \\
n(\%)\end{array}$} & \multirow[b]{2}{*}{$\begin{array}{l}\text { Do not know } \\
n(\%)\end{array}$} & \multirow[b]{2}{*}{$\begin{array}{l}\text { Prefer not to say } \\
n(\%)\end{array}$} \\
\hline & & $\begin{array}{l}>10 \% \\
n(\%)\end{array}$ & $\begin{array}{l}10 \% \\
n(\%)\end{array}$ & $\begin{array}{l}<10 \% \\
n(\%)\end{array}$ & $\begin{array}{l}\text { Any } \\
n(\%)\end{array}$ & & & \\
\hline \multirow[t]{5}{*}{ Education level } & $\begin{array}{l}\text { Less than primary } \\
\text { completed }\end{array}$ & $18(13)$ & $20(14)$ & $26(18)$ & $64(45)$ & $38(27)$ & $33(23)$ & $6(4)$ \\
\hline & Primary completed & $95(15)$ & $105(17)$ & $74(12)$ & $274(44)$ & $128(21)$ & $171(28)$ & $43(7)$ \\
\hline & Secondary completed & $694(18)$ & $817(21)$ & $471(12)$ & $1982(50)$ & $801(20)$ & $1019(26)$ & $140(4)$ \\
\hline & University completed & $786(23)$ & $786(23)$ & $408(12)$ & $1980(58)$ & $619(18)$ & $714(21)$ & $75(2)$ \\
\hline & Not answered & $9(8)$ & $9(8)$ & $4(3)$ & $22(18)$ & $22(18)$ & $50(42)$ & $25(21)$ \\
\hline \multirow[t]{4}{*}{ Political ideology } & Left & $520(28)$ & $505(27)$ & $179(10)$ & $1204(64)$ & $205(11)$ & $433(23)$ & $25(1)$ \\
\hline & Central & $573(18)$ & $750(23)$ & $460(14)$ & $1783(55)$ & $627(19)$ & $752(23)$ & $86(3)$ \\
\hline & Right & $321(18)$ & $323(18)$ & $262(15)$ & $906(51)$ & $564(32)$ & $259(15)$ & $55(3)$ \\
\hline & Missing & $188(14)$ & $159(12)$ & $82(6)$ & $429(33)$ & $212(16)$ & $543(42)$ & $123(9)$ \\
\hline \multirow[t]{3}{*}{ Altruism } & Meagre & $366(16)$ & $483(22)$ & $303(14)$ & $1152(52)$ & $584(26)$ & $450(20)$ & $34(2)$ \\
\hline & Not answered & $518(16)$ & $518(16)$ & $343(10)$ & $1379(42)$ & $600(18)$ & $1096(33)$ & $206(6)$ \\
\hline & Generous & $718(27)$ & $736(27)$ & $337(12)$ & 1791 (66) & $424(16)$ & $441(16)$ & $49(2)$ \\
\hline \multirow[t]{3}{*}{ Income } & Low & $670(19)$ & $715(20)$ & $452(13)$ & $1837(52)$ & $720(20)$ & 863 (24) & $108(3)$ \\
\hline & High & $774(21)$ & $844(23)$ & $443(12)$ & $2061(57)$ & $743(21)$ & $746(21)$ & $69(2)$ \\
\hline & Missing & $158(15)$ & 178 (17) & $88(8)$ & $424(40)$ & $145(14)$ & $378(36)$ & $112(11)$ \\
\hline \multirow[t]{2}{*}{ Gender } & Female & $753(19)$ & $869(21)$ & $422(10)$ & $2044(50)$ & $652(16)$ & $1208(30)$ & $155(4)$ \\
\hline & Male & $849(20)$ & $868(21)$ & $561(14)$ & $2278(55)$ & $956(23)$ & 779 (19) & $134(3)$ \\
\hline \multirow[t]{3}{*}{ Age } & Young & $635(22)$ & $647(23)$ & $337(12)$ & $1619(57)$ & 487 (17) & $611(21)$ & $126(4)$ \\
\hline & Mid & $542(18)$ & $594(20)$ & $373(12)$ & $1509(50)$ & $635(21)$ & 784 (26) & $86(3)$ \\
\hline & Old & $425(18)$ & $496(21)$ & $273(12)$ & $1194(51)$ & $486(21)$ & $592(25)$ & 77 (3) \\
\hline \multirow{3}{*}{$\begin{array}{l}\text { Willingness to } \\
\text { take risks with } \\
\text { health }\end{array}$} & Not answered & $65(11)$ & $64(11)$ & $30(5)$ & $159(28)$ & $82(14)$ & $258(45)$ & $73(13)$ \\
\hline & Unwilling & 888 (18) & 1115 (22) & $583(12)$ & $2586(52)$ & 965 (19) & $1304(26)$ & $155(3)$ \\
\hline & Willing & $649(25)$ & $558(21)$ & $370(14)$ & $1577(60)$ & $561(21)$ & 425 (16) & $61(2)$ \\
\hline
\end{tabular}


Fig. 2 Bayesian ordinal logistic regression estimates of single variable odds ratios of greater willingness to donate COVID-

19 vaccines
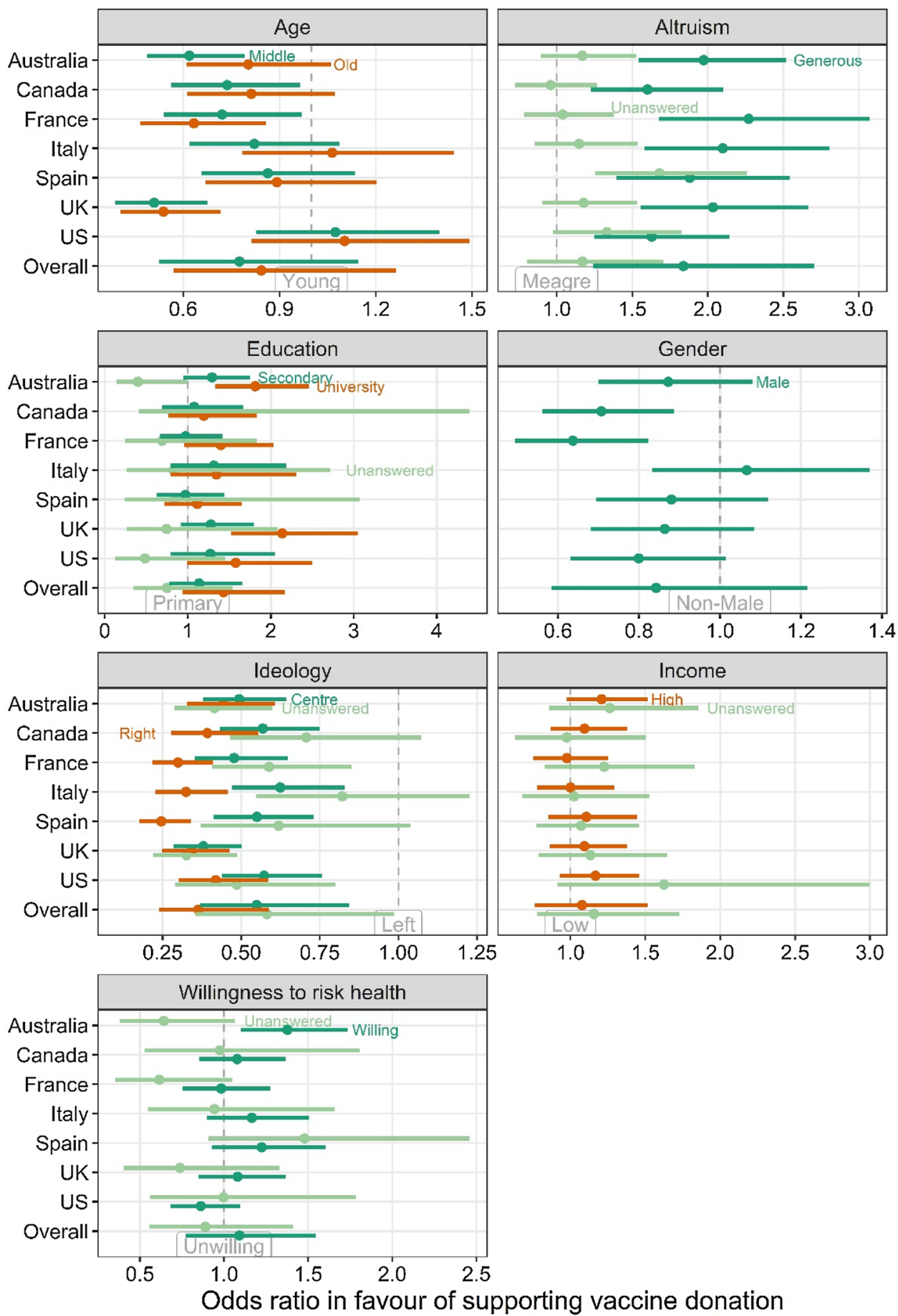

was for no donation (Table 1). ${ }^{8}$ For example, while $64 \%$ (95\% CI 62-67) of those on the political left supported donation (vs. $11 \%$ (95\% CI 10-12) no donation), $51 \%$ (95\% CI 48-53) of those on the political right also supported donation (vs. 32\% (95\% CI 29-34) no donation).

\footnotetext{
${ }^{8}$ The only exception was those with unanswered data for education, where support was equally divided between some level of donation and no donation.
}

\subsection{Single Variable Models}

The results of the deviance information criteria (DIC) tests indicated that, for every variable, the random model was preferred (Electronic Supplementary Material (ESM), Appen$\operatorname{dix}$ A). Results from the univariate Bayesian ordered logistic regression models, all with random country effects as indicated by DIC, are plotted in Fig. 2 (see ESM, Appendix B, Tables B1-B7 for all odds ratio estimates and 95\% credible 
Table 2 Estimates from univariate Bayesian ordered logistic regressions of overall odds ratios of greater willingness to donate COVID19 vaccines

\begin{tabular}{|c|c|c|c|c|}
\hline & Odds ratio & CI lower limit & CI upper limit & BPP \\
\hline \multicolumn{5}{|l|}{ Education } \\
\hline Secondary & 1.14 & 0.78 & 1.66 & 0.473 \\
\hline University & 1.43 & 0.93 & 2.17 & 0.094 \\
\hline Unanswered & 0.75 & 0.35 & 1.54 & 0.426 \\
\hline \multicolumn{5}{|c|}{ Reference: Primary or less } \\
\hline \multicolumn{5}{|l|}{ Political leaning } \\
\hline Centre & 0.55 & 0.37 & 0.84 & 0.012 \\
\hline Right & 0.36 & 0.24 & 0.59 & 0.002 \\
\hline Unanswered & 0.58 & 0.36 & 0.99 & 0.046 \\
\hline \multicolumn{5}{|l|}{ Reference: Left } \\
\hline \multicolumn{5}{|l|}{ Altruism } \\
\hline Unanswered & 1.17 & 0.80 & 1.71 & 0.376 \\
\hline Generous & 1.84 & 1.24 & 2.71 & 0.007 \\
\hline \multicolumn{5}{|l|}{ Reference: Meagre } \\
\hline \multicolumn{5}{|l|}{ Income } \\
\hline High & 1.08 & 0.76 & 1.51 & 0.627 \\
\hline Unanswered & 1.16 & 0.78 & 1.73 & 0.452 \\
\hline \multicolumn{5}{|l|}{ Reference: Low } \\
\hline \multicolumn{5}{|l|}{ Gender } \\
\hline Male & 0.84 & 0.58 & 1.22 & 0.302 \\
\hline \multicolumn{5}{|l|}{ Reference: All other } \\
\hline \multicolumn{5}{|l|}{ Age, years } \\
\hline $40-59$ & 0.78 & 0.53 & 1.15 & 0.180 \\
\hline $60+$ & 0.84 & 0.57 & 1.26 & 0.360 \\
\hline \multicolumn{5}{|c|}{ Reference: 39 and under } \\
\hline \multicolumn{5}{|c|}{ Willingness to take risks with health } \\
\hline Unanswered & 0.89 & 0.56 & 1.41 & 0.593 \\
\hline Willing & 1.09 & 0.77 & 1.55 & 0.585 \\
\hline Reference: Unwilling & & & & \\
\hline
\end{tabular}

The BPP is the estimated probability that the odds ratio is equal to one (the null hypothesis)

BBP Bayesian Posterior Probability, $C I$ confidence interval intervals.) In most cases, across the full-sample of countries, the odds ratios were not significantly different from 1 , as indicated in Table 2 by the $95 \%$ credible intervals not containing 1 (i.e., BPP < 0.05). This suggests only limited heterogeneity in willingness to donate COVID-19 vaccines. An exception was political ideology. As hypothesised, those on the left were significantly more likely to support vaccine donation than those on the right. They were also more likely to support donation that those in the centre or those with unanswered responses for political leaning. This trend was consistent in all countries (Fig. 2 and ESM, Appendix B, Table B2). The only other exception was altruism. As also hypothesised, those who were categorised "generous" were more likely to support vaccine donation than those categorised "meagre". This trend was consistent in all countries (Fig. 2 and ESM, Appendix B, Table B5).

While the odds ratios for university education versus primary or less were in the direction we hypothesised $(>1)$ in all countries, and were significant in Australia and the UK (Fig. 2 and ESM, Appendix B, Table B1), the $95 \%$ credible interval for the overall odds ratio estimate (1.43) contained 1 . While the odds ratios for high income versus low income were also in the direction we hypothesised $(>1)$ in most countries and overall (1.08), all credible intervals contained 1 .

\subsection{Multiple Variable Model}

Figure 3 displays the estimated odds ratios from a multiple variable ordered logistic regression model with independent variables of age, gender, education, political ideology, altruism, income and willingness to take risks with health (see ESM, Appendix B, Table B8 for all odds ratio estimates and $95 \%$ credible intervals).

The results are broadly very similar to the single variable models. Those on the left were again significantly more likely to support vaccine donation than those on the 
Fig. 3 Bayesian multiple variable ordered logistic regression estimates of odds ratios of willingness to donate COVID-

19 vaccines
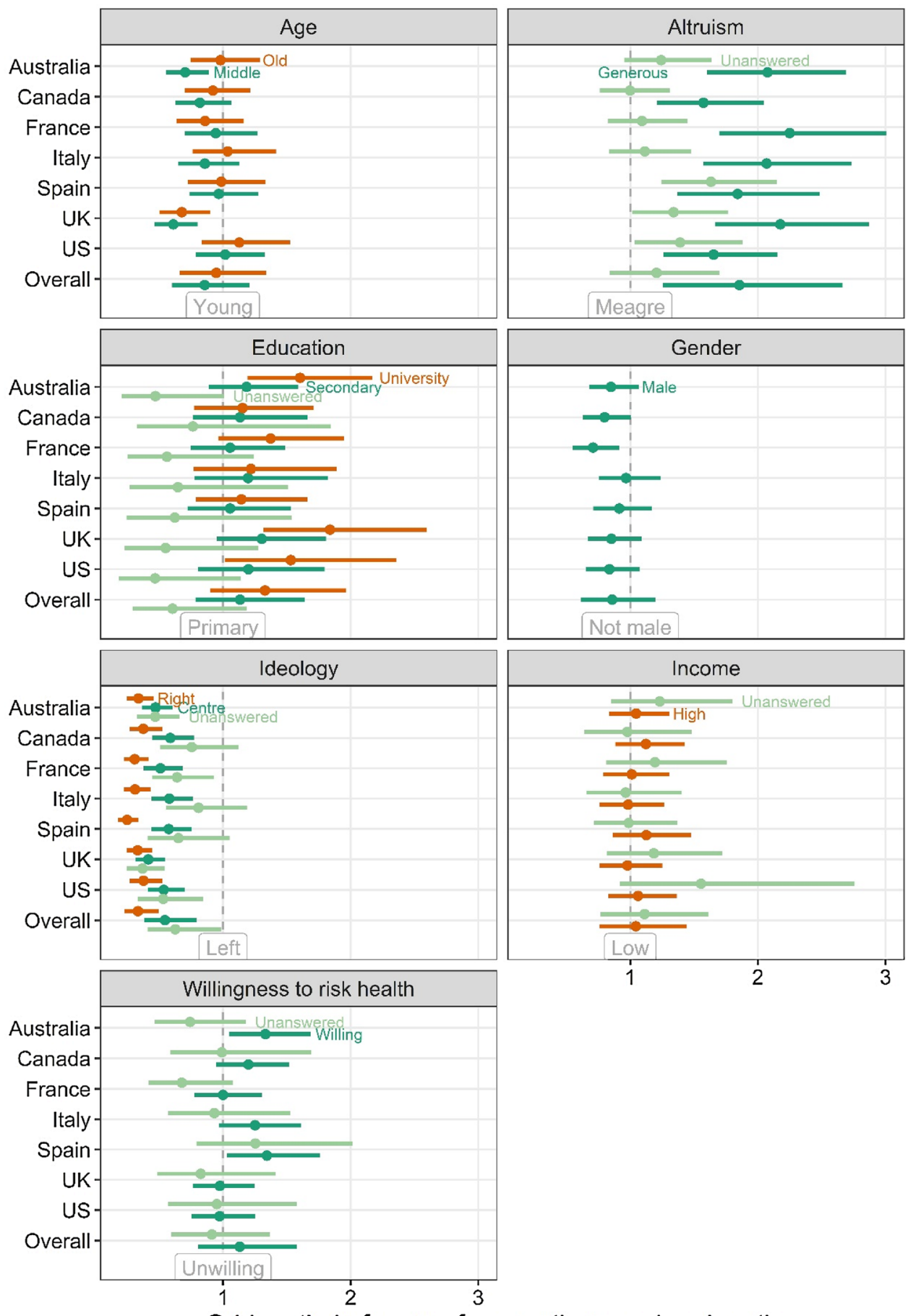

Odds ratio in favour of supporting vaccine donation

right or centre, both overall and in each country. They were also more likely overall, and in most individual countries, to support donation than those with unanswered political ideology. With regard to altruism, those who were categorised "generous" were again more likely to support vaccine donation than those categorised "meagre," both overall and in all countries.
The odds ratios for university education versus primary or less were again in the direction we hypothesised $(>1)$ in all countries, and were significant in Australia, the UK and the USA, but the $95 \%$ credible interval for the overall odds ratio estimate again contained 1 . As in the single variable models, the odds ratios for high income versus low income were also again in the direction we hypothesised $(>1)$ in most countries and overall, but all credible intervals contained 1 . 


\subsection{Sensitivity Analysis}

The analogous results for the single variable and multiple variable ordinal logistic regression models including unanswered responses to the donation question are reported in ESM, Appendix B (Tables B9 and B10) and Appendix C Figs. $\mathrm{C} 1$ and $\mathrm{C} 2$. These results were qualitatively very similar to the main analyses. Those on the left were significantly more likely to support vaccine donation than those on the right or centre or with unanswered responses, both overall and in each country. Those who were categorised "generous" altruistically were more likely to support vaccine donation than those categorised "meagre", both overall and in all countries.

\subsubsection{Those with an Unanswered Ideology}

Focusing on the case of political ideology, in this section we present a short exploratory analysis of the overall donation preferences of those with unanswered responses. ${ }^{9}$ For the purposes of this analysis, respondents were categorised into a binary 'willing/not willing' variable, with responses indicating support for any level of donation $(<10 \%, 10 \%$ or $>10 \%$ ) defined as willing, and all other responses defined as 'not willing'. ESM, Appendix D, Table D1 shows the numbers and percentages of those who were willing, and those who were not willing, to donate COVID-19 vaccines. The results are stratified by country and whether the ideology was unanswered or not.

In every country the percentage willing to donate COVID-19 vaccines was much lower in the group that did not answer the ideology question, ranging from 16 percentage points lower in Canada to 40 percentage points in the USA.

\section{Discussion}

Beyond ethical considerations, there are compelling arguments that it is in the self-interest of HICs to donate substantial quantities of vaccine doses to countries unable to acquire sufficient quantities on their own. The recent emergence of the more transmissible so-called delta COVID-19 variant [19], first observed in India [20] during an intense surge of infections, underscores the maxim that "no-one is safe until everyone is safe".

The appetite of HIC governments to make COVID-19 vaccine doses available globally is likely to hinge largely on public support. As reported in Clarke et al. [12], the

\footnotetext{
9 Unanswered response for political ideology was found to be correlated with unanswered response for other variables in the dataset.
}

CANDOUR study found that there are overall strong levels of public support for COVID-19 vaccine donation, across seven HICs-a finding consistent with another recent survey-based study focused on the USA [21]. The present study extends these results by providing evidence that, encouragingly, this strong support is fairly broad-based. We found no strong evidence overall for our hypothesis that support for donations would be significantly higher among those with a university education, though there was evidence in some countries. While, as we hypothesised, support among those on the political right for donation was lower than among those on the left (consistent with [21]), 51\% of respondents who identified with the right still supported some level of donation. Similarly, though those in the more altruistic half of the sample were, as hypothesised, more likely to support donation than those who were not, over half of the less altruistic 'meagre' group still supported some level of donation. ${ }^{10}$

\subsection{Limitations}

There are two main limitations to the study. First, as is inherent to all online studies, the need for access to a computer or personal device means that the online samples in each country may differ from their populations in important respects. The CANDOUR study country samples are broadly representative of their populations at least on the observable measures we can benchmark against, including gender, education, income and region [15]. However, as discussed by Duch et al. [15], it is possible that the online samples may differ from their populations on important unobservable variables, such as political engagement and general knowledge. This could potentially reduce the generalisability of our results.

Second, the views captured by our survey are a snapshot of public opinion at a particular period of time (November-December 2020). Notably, at that time, COVID-19 vaccines had been found to be effective and the distribution of COVID-19 vaccines was no longer a hypothetical question. While public opinion may well have changed since this time, there are reasons to conjecture that current opinion in HICs may be more strongly supportive of vaccine donation. First, increasingly large proportions of respondents in HIC have now been vaccinated, which may reduce the public's concerns that donating doses to other countries would mean that they would need to wait longer to be vaccinated. Second, as of November-December 2020, there had been very limited public discussion of the risk that future variants of

\footnotetext{
10 The fact that those in the more altruistic half of the sample were more likely to support donation might be regarded as providing some reassurance in the study results. The results would, arguably, lack face validity if more generous respondents were not found to be more likely to support donation.
} 
COVID-19 might emerge that could be more transmissible and, crucially, more resistant to current vaccines. This is no longer the case, and the public may now be more likely to see a link between large numbers of infections overseas and the risk of variants emerging that are more resistant to our vaccines.

\section{Conclusion}

To conclude, the evidence provided in this study suggests that the strong support for COVID-19 vaccine donation presented by Clarke et al. [12] is fairly broad-based in terms of age, gender, socio-economic status and political ideology. We hope that these findings will encourage policymakers in HIC to act decisively to ensure truly global access to COVID-19 vaccines and expedite bringing the pandemic to an end.

Supplementary Information The online version contains supplementary material available at https://doi.org/10.1007/s40258-021-00696-8.

\section{Declarations}

Ethics declarations The survey study was approved by the University of Oxford Medical Sciences Interdivisional Research Ethics Committee (Approval ID: R72328/RE001). Informed consent was obtained from all survey participants.

Funding The research was supported by the National Institute for Health Research (NIHR) Oxford Biomedical Research Centre (BRC) and the COVID-19 Oxford Vaccine Trial. The views expressed are those of the author(s) and not necessarily those of the NHS, the NIHR or the Department of Health and Social Care. Adrian Barnett received funding from the National Health and Medical Research Council. Mara Violato receives funding from the National Institute for Health Research (NIHR) Applied Research Collaboration Oxford and Thames Valley at Oxford Health NHS Foundation Trust.

Conflict of interest All authors report no conflicts of interest.

Author contributions LSJR: survey design; pre-specified hypotheses; interpretation of results; led drafting of manuscript; project administration. AB: statistical analysis; led drafting of methods section; interpretation of results; contributed to drafting the manuscript. PC: contributed to drafting the manuscript; revised the paper critically for intellectual content. MV: survey design; contributed to drafting the manuscript; revised the paper critically for intellectual content; project administration. RD: contributed to drafting the manuscript; revised the paper critically for intellectual content; overall design of the CANDOUR study; project administration. PMC: contributed to drafting the manuscript; revised the paper critically for intellectual content; overall design of the CANDOUR study; project administration. All authors contributed to the manuscript and approved the final version.

Data and code availability The Bayesian models and $\mathrm{R}$ code are freely available on github (https://github.com/agbarnett/donate). All data will be made available on github upon publication.
Consent to participate All participants were provided with participant information when they entered the online survey and consented to participate in the study.

Consent for publication All participants were provided with participant information when they entered the online survey and consented to publication of the results of this study.

Open Access This article is licensed under a Creative Commons Attribution-NonCommercial 4.0 International License, which permits any non-commercial use, sharing, adaptation, distribution and reproduction in any medium or format, as long as you give appropriate credit to the original author(s) and the source, provide a link to the Creative Commons licence, and indicate if changes were made. The images or other third party material in this article are included in the article's Creative Commons licence, unless indicated otherwise in a credit line to the material. If material is not included in the article's Creative Commons licence and your intended use is not permitted by statutory regulation or exceeds the permitted use, you will need to obtain permission directly from the copyright holder. To view a copy of this licence, visit http://creativecommons.org/licenses/by-nc/4.0/.

\section{References}

1. Mullard A. How COVID vaccines are being divvied up around the world. Nature. 2020;2020:30.

2. Duke Global Health Innovation Center. Launch and Scale Speedometer. Duke University. 2020. https://launchandscalefaster.org/ COVID-19. Accessed 9 Mar 2021.

3. Editorial. Why a pioneering plan to distribute COVID vaccines equitably must succeed. Nature 2021;589:170.

4. Yamey G. Rich countries should tithe their vaccines. Nature. 2021;590(7847):529.

5. Speech by WHO Director General at Media Briefing on 14th May 2021. 2021. https://news.un.org/en/story/2021/05/1091952.

6. Pollard A. Rich countries have a moral duty to share their COVID-19 shots. The Conversation. 2021. https:// theconversation.com/oxford-vaccine-professor-rich-count ries-have-a-moral-duty-to-share-their-covid-19-shots-160116.

7. White House Statement. 2021. https://www.whitehouse.gov/brief ing-room/statements-releases/2021/06/13/fact-sheet-united-statesand-g7-partners-will-provide-more-than-2-billion-vaccines-for-theworld/. Accessed 13 Jun 2021.

8. Wise J. Covid-19: G7 vaccine promises fail to meet scale of challenge, say critics. BMJ. 2021;373:n1520.

9. Kumar S, Quinn SC, Kim KH, Hilyard KM. US public support for vaccine donation to poorer countries in the 2009 H1N1 pandemic. PLoS ONE. 2012;7(3):e33025.

10. Çakmaklı C, Demiralp S, Kalemli-Özcan S, Yeşiltaş S, Yıldırım MA. The economic case for global vaccinations: an epidemiological model with international production networks. In: National Bureau of Economic Research Working Paper No. number 28395. 2021. https://doi.org/10.3386/w28395.

11. Hafner M, Yerushalmi E, Fays C, Dufresne E, Van Stolk C. COVID19 and the cost of vaccine nationalism. Santa Monica, CA: RAND Corporation. 2020. https://www.rand.org/pubs/research_reports/ RRA769-1.html. Accessed 18 Dec 2020.

12. Clarke PM, Roope LSJ, Loewen PJ, Bonnefon JF, Melegaro A, Friedman J, Violato M, Barnett A, Duch R. Public opinion on global rollout of COVID-19 vaccines. Nat Med. 2021;30:1-2.

13. Kahane LH. Politicizing the mask: political, economic and demographic factors affecting mask wearing behavior in the USA. East Econ J. 2021;47(2):163-83. 
14. Clarke P, Duch RM, Roope L, Violato M. CANDOUR Pre-Registration: COVID-19 Vaccine Preference and Opinion Survey. 2021. https://osf.io/x4yru/.

15. Duch R, Roope LSJ, Violato M, et al. Citizens from 13 countries share similar preferences for COVID-19 vaccine allocation priorities. Proc Natl Acad Sci. 2021;118:38.

16. Dobson AJ, Barnett AG. An introduction to generalized linear models. 4th ed. Texts in Statistical Science. Chapman \& Hall/CRC, Boca Raton. 2018.

17. Spiegelhalter DJ, Best NG, Carlin BP, van der Linde A. The deviance information criterion: 12 years on. J R Stat Soc Ser B (Stat Methodol). 2014;76(3):485-93.
18. MRC Statistics Unity, University of Cambridge. 2021. https://www. mrc-bsu.cam.ac.uk/software/bugs/the-bugs-project-dic/\#q9.

19. Torjesen I. Covid-19: delta variant is now UK's most dominant strain and spreading through schools. BMJ. 2021;373:n1445.

20. Wise J. Covid-19: UK cases of variant from India rise by $160 \%$ in a week. BMJ. 2021;373:n1315.

21. Guidry JP, Perrin PB, Laestadius LI, Vraga EK, Miller CA, Fuemmeler BF, Burton CW, Ryan M, Carlyle KE. US public support for COVID-19 vaccine donation to low-and middle-income countries during the COVID-19 pandemic. Vaccine. 2021;39(17):2452-7. 